$$
639908624
$$

NUREG / CR -4543

SAND86-0462

RV

Printed April 1986
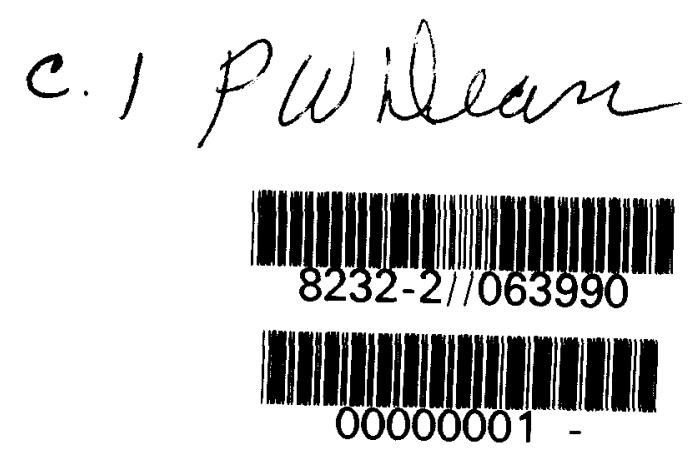

\title{
First Results From Electron-Photon Damage Equivalence Studies on a Generic Ethylene-Propylene Rubber
}

\author{
W. H. Buckalew
}

Prepared by

Sandia National Laboratories

Albuquerque, New Mexico 87185 and Livermore, California 94550

for the United States Department of Energy

under Contract DE-AC04-76DP00789 


\section{NOTICE}

This report was prepared as an account of work sponsored by an agency of the United States Government. Neither the United States Government nor any agency thereof, or any of their em ployees, makes any warranty, expressed or implied, or assumes any legal liability or responsibility for any third party's use, or the results of such use, of any information, apparatus product or process disclosed in this report, or represents that its use by such third party would not infringe privately owned rights.

Available from

Superintendent of Documents U.S. Government Printing Office

Post Office Box 37082

Washington, D.C. 20013-7982

and

National Technical Information Service

Springfield, VA 22161 
NUREG/CR-4543

SAND86-0462

RV

\section{FIRST RESULTS FROM ELECTRON-PHOTON DAMAGE EQUIVALENCE STUDIES ON A GENERIC ETHYLENE-PROPYLENE RUBBER}

W. H. Buckalew

April 1986

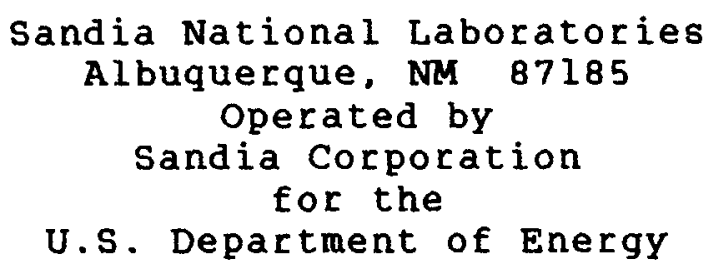

Prepared for

Electrical Engineering Instrumentation and Control Branch Division of Engineering Technology office of Nuclear Regulatory Research

U.S. Nuclear Regulatory Commission

Washington, DC 20555

Under Memorandum of Understanding DOE 40-550-75

NRC EIN NO. A-105I 


\section{ABSTRACT}

As part of a simulator adequacy assessment program, the relative effectiveness of electrons and photons to produce damage in a generic ethylene-propylene rubber (EPR) has been investigated. The investigation was limited in extent in that a single EPR material, in three thicknesses, was exposed to Cobalt-60 photons and three electron beam energies.

Basing material damage on changes in the EPR mechanical properties elongation and tensile strength, we observed that EPR damage was a smoothly varying function of absorbed energy and independent of irradiating particle type. EPR damage tracked equally well as a function of both incident particle energy and material front surface dose.

Based on these preliminary data, we tentatively concluded that a correlation between particle, particle energy, and material damage (as measured by changes in material elongation and/or tensile strength) has been demonstrated. 


\section{.}


Executive sumary. . . . . . . . . . . . . . .

1.0 Introduction . . . . . . . . . . . . . . . . 2

2.0 Apparatus and Procedures . . . . . . . . . . . 5

3.0 Results. . . . . . . . . . . . . . . . . . . . . . 13

3.I Elongation and Tensile strength versus Particle Energy . . . . . . . . . .

3.2 Elongation and Tensile strength versus Absorbed Energy . . . . . . . . . .

3.3 Elongation and Tensile strength versus Front Surface Dose... . . . . . . .

3.4 Photon to Electron Relative Effectiveness

Estimates. . . . . . . . . . . . . . . . . 19

4.0 Conclusions. . . . . . . . . . . . . . . . . . . 24

References. . . . . . . . . . . . . . . . . . . 28 


\section{LIST OF FIGURES}

Page

1. Beta Particle Time-Dependent Average Energy. . . . . 3

2. Reactor Containment Volume Beta Particle

Radiation Environment. . . . . . . . . . . . . . . . 4

3. Schematic of Experiment orientation. . . . . . . . . 6

4. Calculated Electron and Photon Energy Deposition in Ethylene-Propylene Rubber Insulation . . . . . . . .

5. Material Elongation versus Particle EnergyAveraged Data. . . . . . . . . . . . . . . . . . . 14

6. Material Elongation versus Particle Energy . . . . . 16

7. Material Tensile strength versus Particle EnergyAveraged Data. . . . . . . . . . . . . . . . . 17

8. Material Tensile Strength versus Particle Energy . . $\quad 18$

9. Material Elongation versus Absorbed Energy . . . . . 20

10. Material Tensile Strength versus Absorbed Energy . . 21

11. Material Elongation versus Front Surface Dose. . . . . 22

12. Material Tensile strength versus Front surface Dose. . 23

13. Photon to Electron Effectiveness Ratio Elongation Estimate. . . . . . . . . . . . . . . 25

14. Photon to Electron Effectiveness Ratio Tensile strength Estimate. 


\section{LIST OF TABLES}

Page

1. Energy Deposition Synopsis - $0.10 \mathrm{~cm}$ EPR Slab. . . . . 10

2. Energy Deposition - All Slab Thicknesses . . . . . . . 10

3. Front Surface Dose - All slab Thicknesses. . . . . . . 12 


\section{ACKNOWLEDGMENT}

The author would like to gratefully acknowledge the valuable

technical assistance provided by $S$. M. Luker during the course of this work. 


\section{EXECUT IVE SUMMARY}

As part of a study on the adequacy of cobalt-60 sources to simulate the radiation damage to organic materials exposed to the mixed radiation environment accompanying a nuclear power plant loss of coolant accident (LOCA), the "equivalence" of electron and photon induced damage in a generic ethylene propylene rubber (EPR) insulation material exposed to cobalt-60 photons and accelerator produced electron beams was investigated.

Electron beam induced material damage was studied as a function of three EPR thicknesses, three electron beam energies, and one dose-rate and integrated dose. EPR thicknesses were selected as being representative of those used in electrical cable insulation applications. Likewise, electron beam energies were chosen to be comparable to those predicted for a LOCA event. The electron beam dose-rate was also chosen on the basis of estimated LOCA dose-rates, and the integrated dose was selected to balance the need for statistically significant material damage and reasonable electron beam exposure times. Cobalt-60 irradiations, equivalent to the electron beam exposure dose and dose-rate, were obtained for the material damage equivalence evaluation.

Damage to irradiated materials was based on a technique frequently used to gauge the effects of radiation aging on Class $1 \mathrm{E}$ elastomeric materials: i.e. changes in elongation and tensile strength of the irradiated specimens. Analyses of the radiation exposure data suggest that the observed material damage is a slowly varying function of absorbed energy and independent of particle type within experimental uncertainty. Absorbed energy. particle energy, and surface dose are all interrelated parameters. and the data analysis on the basis of each of these parameters yields similar results. From these data an estimate of photon to electron relative (damage) effectiveness was obtained. The ratio lies between 0.94 and 1.04 over the range of parameters considered to date.

More extensive studies are required to reach conclusions applicable to other materials and radiation exposure conditions. In particular, the study should consider (at least one) other material, extend the electron energy to lower values and the total dose to higher values, and evaluate the effect of dose rate. Consideration of an additional material would provide a check on the uniqueness of the results presented here. Extension of the electron energy to lower values may provide a cut-off energy below which incident particles could be neglected. Larger total absorbed doses would allow determination of the influence of degradation extent. Dose-rate data would establish a saturation effect, if there is one and perhaps provide a measure of dose-rate influence on the damage effectiveness of electron beam irradiations as a function of beam energy. 
It is the general practice in the qualification testing of safetyrelated systems and components to simulate reactor containment volume radiation environments, resulting from loss of coolant accidents (LOCA), with isotopic photon irradiators. Implicit here is the assumption that discrete energy, steady-state photon sources will adequately simulate a complex radiation environment composed of electron and photon components each with its own time dependent energy spectrum and emission rate.

In view of the complexity of the accident radiation environment, the adequacy of isotopic photon irradiators to simulate the accident conditions has been periodically questioned. It has been our contentionl that equivalence exists between electron and photon radiation effects provided certain conditions are satisfied. On a microscopic scale, we believe equivalence is likely present provided equal energy absorption occurs with either electron or photon bombardment. On a macroscopic scale, however. nonequivalence of electron/photon bombardment may be observed. Several factors may influence equivalence and include, for example. (1) differences in energy deposition profiles between electrons and photons, (2) differences in material response (energy deposition), per unit dosimeter response, as a function of irradiating particle type, and (3) different damage mechanisms (such as crosslinking. charge buildup and/or breakdown, etc.). On the other hand, irradiated material properties may be so insensitive to the type and energy of the incident radiation that these parameters--energy, particle-type, etc.--are mere nuances as far as damage studies are concerned. Our intent was to identify the degree to which each of these functions influence damage equivalence in certain organic materials.

Recently we completed a scoping study on the relative effectiveness of electron and photon bombardment in producing radiation damage in a rubber insulation material. We examined the response of a generic EPR rubber. 2 in slab geometry, to both cobalt-60 photons ( $E$ (ave) $=1.25 \mathrm{MeV}$ ) and several different energy electron beams. Rubber thicknesses were $0.1,0.15$, and $0.2 \mathrm{~cm}$; this is the thickness range frequently used in electrical insulation applications. Electron energies considered spanned the range between 0.235 and $0.85 \mathrm{MeV}$ and were based on beta particle average energy estimates for in-containment radiation environments resulting from a LOCA radiation release. For comparison with our choice of energies those calculated average energy estimates for a beta particle LOCA radiation environment are presented in Figure 1.3 The electron dose-rate and integrated dose were fixed at $2 \mathrm{Mrad} / \mathrm{hr}$ and $10 \mathrm{Mrad}$ respectively and both were chosen somewhat arbitrarily. As may be observed from the calculated LocA dose-rate/dose plot. Figure 2,4 the $2 \mathrm{Mrad} / \mathrm{hr}$ electron dose rate occurs at an integrated dose of approximately 100 Mrads--well. 


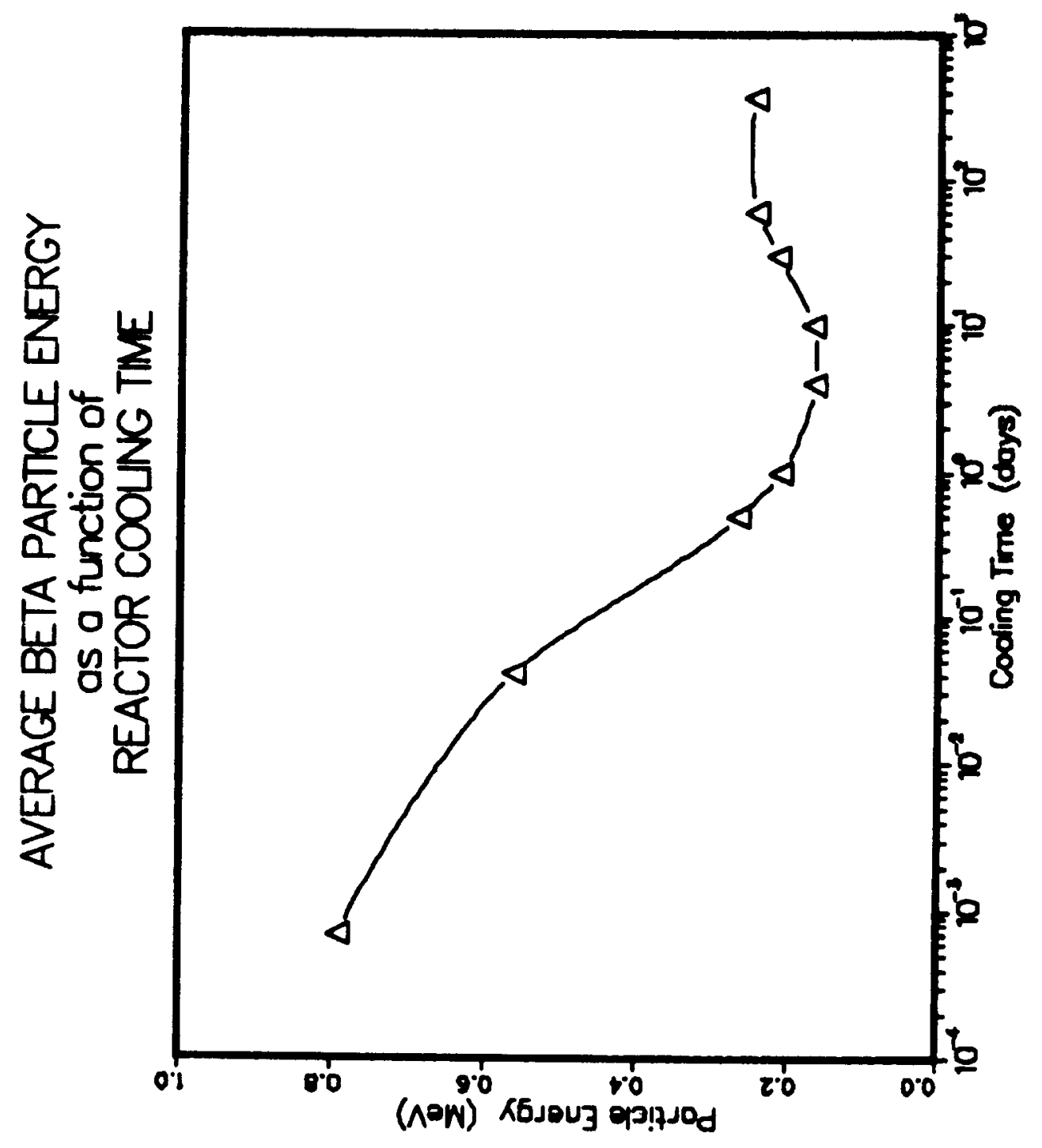




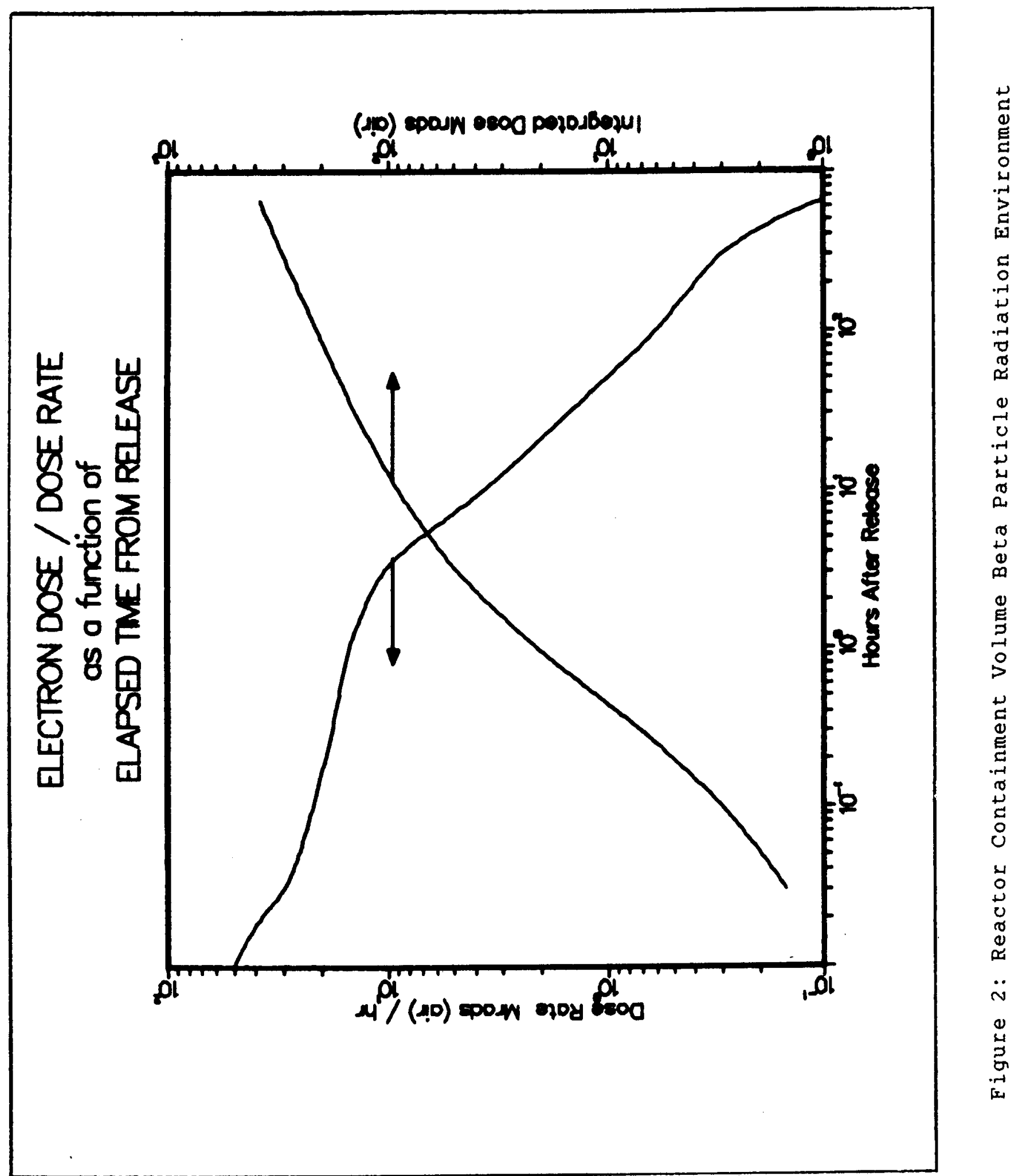


within the LOCA dose-rate versus time profile. The integrated dose was selected on the basis of consistent material properties degradation and reasonable radiation exposure times.

Complimentary to the experiments, we calculated the EPR response to both photon and electron beams as energy deposition profiles. sample front surface dose, and total energy absorption. In addition, response of the dosimetry material used in the study was also calculated. The calculated EPR response allowed correlation of observed EPR damage to front surface dose, etc. Calculated dosimetry response provided correlation between calculated photon and electron results just as dosimetry measurements provided a link between observed photon and electron induced damage.

The following sections of the report detail the electron/photon scoping study. Included are discussions of the experimental procedures, experimental and calculated results, and conclusions.

\section{APPARATUS AND PROCEDURES}

We used a PELLETRON* electron beam accelerator to produce the electron beam exposures for our experiments. The electron energy range is continuously variable between 0.025 and $1.15 \mathrm{MeV}$, and beam current is adjustable up to a maximum of 34 microamperes. Uncertainties in the machine parameters (voltage regulation and ripple) were carefully determined such that the electron beam energy was known to within approximately 0.5 percent. 5 Total beam current was measured with an in-line Faraday Cup positioned at the accelerator exit and just inside the integral vacuum chamber. Additional current sensitive elements were positioned within the vacuum chamber as aids in controlling the electron beam trajectory. In Figure 3 a schematic of the accelerator, integral vacuum chamber, and external fixturing are depicted. All internal and external elements are positioned along a common centerline that is also colinear with the required electron beam trajectory. In the vacuum chamber, maximum current into the deflection coils is obtained by minimizing current detected by the focussing and alignment apertures. The normally tight electron beam is then deflected into a square pattern and transported into the ambient enviconment through a $0.005 \mathrm{~cm}(0.002$ in) beryliium window. Deflection system performance has been well characterized 6 as a function of electron beam energy, beam pattern size required, etc. Fixturing external to the vacuum chamber consists of a beryllium shutter, beryllium back plane, and

* Manufactured by National Electrostatics Corp.. Middleton. WI 


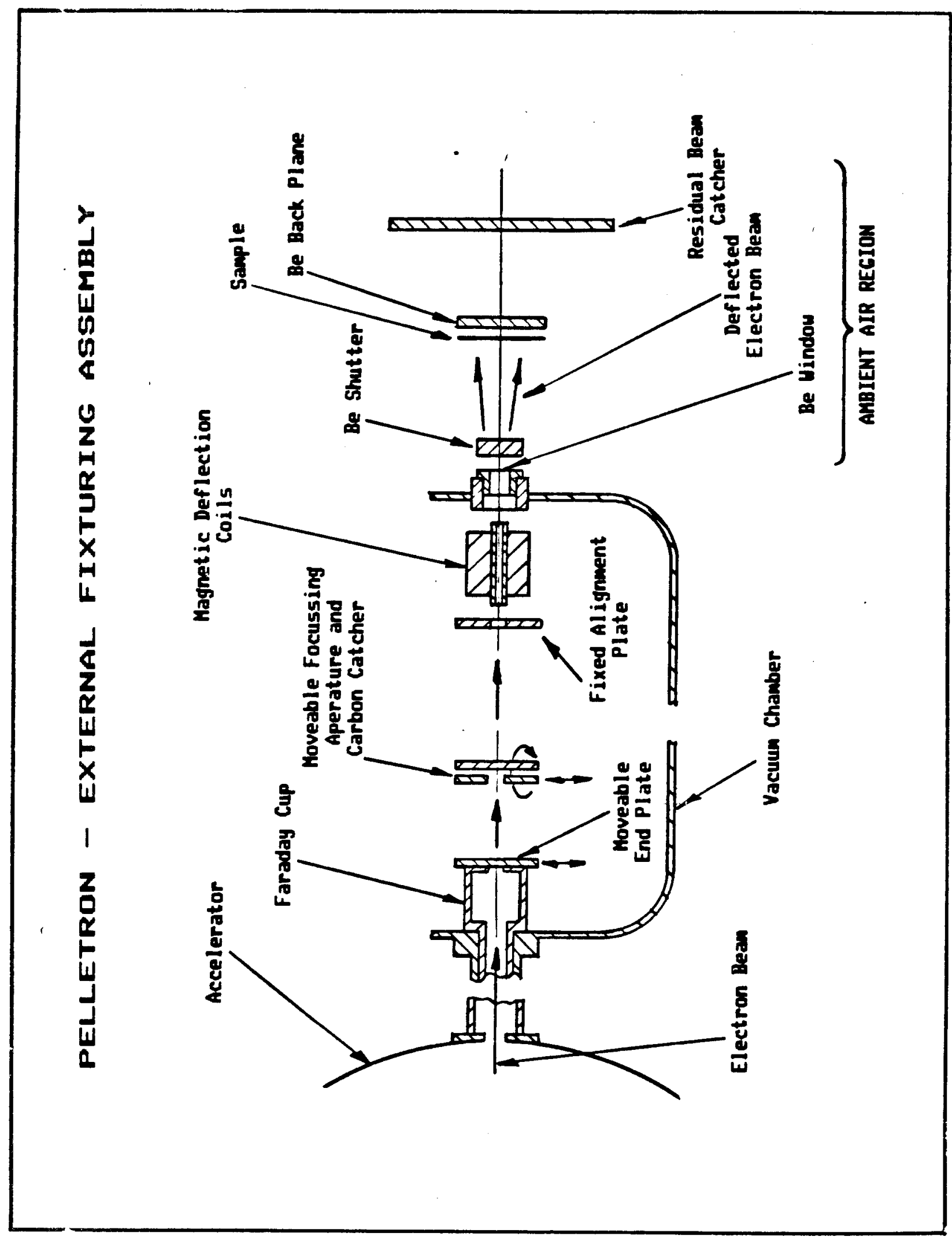

D 
a residual beam catcher. The purpose of the beryllium shutter is twofold--to detect the total beam transported through the beryllium window and isolate target materials from the electron beam during minor beam steering adjustments. The beryllium back plane functions primarily to detect current in the target plane both with and without a test specimen in position. The residual beam catcher functions mainly as a check on current conservation in the ambient environment. Each current detecting element in the array is monitored with an analogue electrometer system. Position of the target plane (beryllium back plane) with respect to the beryllium exit window is determined, primarily, on the basis of geometric considerations. Given the maximum (line-of-sight) dimension subtended from the deflection coil center to the beryllium exit window allows estimation of the window-target plane separation required for a given target specimen size. Some adjustments in window-target plane separation are occasionally required to enhance beam uniformity in the target plane.

Photon exposures were obtained using the Sandia Laboratories North Gama Irradiation Facility (NGIF). In essence, the facility consists of a dry irradiation cell (cubical in shape) and companion rectangular array (12 $\times 10 \times 7$ inches $)$ of cobalt-60 pencils. The source array consists of 64 pencils with total source strength of approximately 55 kilocuries. Dose rate in the vicinity of the $10 \times 12$ inch surface is in excess of $2.5 \mathrm{Mrad}$ (air)/hr.

Extensive electron and photon dosimetry measurements were made prior to the effects experiments. The electron beam pattern size and uniformity data were obtained using thin dye loaded plastic detector material. Detector material response measurements and calibration techniques are similar to those described in Reference 6 . In addition to thin film dosimetry determinations, we converted beryllium back plane current measurements into doserate values using calculated energy absorption coefficients in a manner analogous to those techniques reported in Reference 6 . Photon beam pattern size, uniformity, and dose were also obtained using the thin film dosimetry. Use of identical dosimetry methods, for both electron and photon measurements, allowed for direct comparison of radiation effects data for "equivalence" purposes.

Average electron beam energy incident on the target plane was calculated using the coupled electron-photon transport code. TIGER. 7 Using, as input, the in vacuo electron beam energy determined from the accelerator adjustable parameters. the target plane beam energy was calculated on the basis of beam transport through the beryllium window and intervening window-target plane air gap. In addition to electron spectral data, the calculations yielded test specimen energy deposition data, dosimetry material response, etc. These data were used in minor adjustments of 
input energy and air gap dimension to obtain the desired beam energy at the target plane and yet achieve acceptable beam uniformity across the target plane. Similar calculations were required to obtain energy deposition estimates for samples irradiated in the NGIF Co60 facility. As in the case of the electron beam calculations. we included the effects of intervening material on the deposition results. In this instance, we included the source pencil cladding material as well as the intervening air gap. Likewise, target geometries and compositions were identical to those used in the experiments. Some results of these calculations are given in Figure 4 and Tables 1 and 2 . In Figure 4 energy deposition results for ethylene-proplyene rubber (EPR) are presented. Plotted are deposition data for three electron energies and co60 photons. The listed electron energies are spectral averaged values. whereas the photon value is merely the simple average (1.25) of the two emission lines, i.e., 1.33 and $1.18 \mathrm{Mev}$. In the figure, the energy deposition values have been normalized on the basis of the thin film detector calculated response. This normalization allows for direct comparison of all observed radiation damage, independent of particle type or energy. We note from the figure that the electron energy deposition profiles are strongly dependent on the electron beam energy. Whereas the extrapolated front surface doses are clustered rather closely about a single value.

A compilation of calculated energy deposition data for $0.10 \mathrm{~cm}$ (thick) EPR and detector (dosimeter) material is given in Table 1. It may be noted, in columns 2,3 , and 4 , that the calculated energy deposition results are presented on the basis of one incident particle (MeV/pr, etc.). Experimentally, electron energy deposition determinations are quickly obtained from electron particle (current) measurements in conjunction with calculated data similar to that given in columns 2,3 , and 4 . on the other hand direct determination of high intensity photon particle fluence is not readily obtainable. Hence, we use thin film dosimetry, the detector, as a link between electron and photon exposures rather than particle fluence. In columns 5 and 6 absorbed energy and front surface dose values, based on the detector dose, are tabulated. All absorbed energy and front surface dose values used throughout this report are based on detector response rather than incident particle values.

Calculated energy deposition results, for all material thicknesses, are presented in Table 2. Tabulated are absorbed energy values, per unit detector dose, for each energy particle and EPR thickness. Energy absorption values are based on unit material thickness. We note, from Figure 4, that in several instances sample thickness is greater than the incident particle range and in others particle range is much greater than sample thickness. Further, material degradation is a function of 


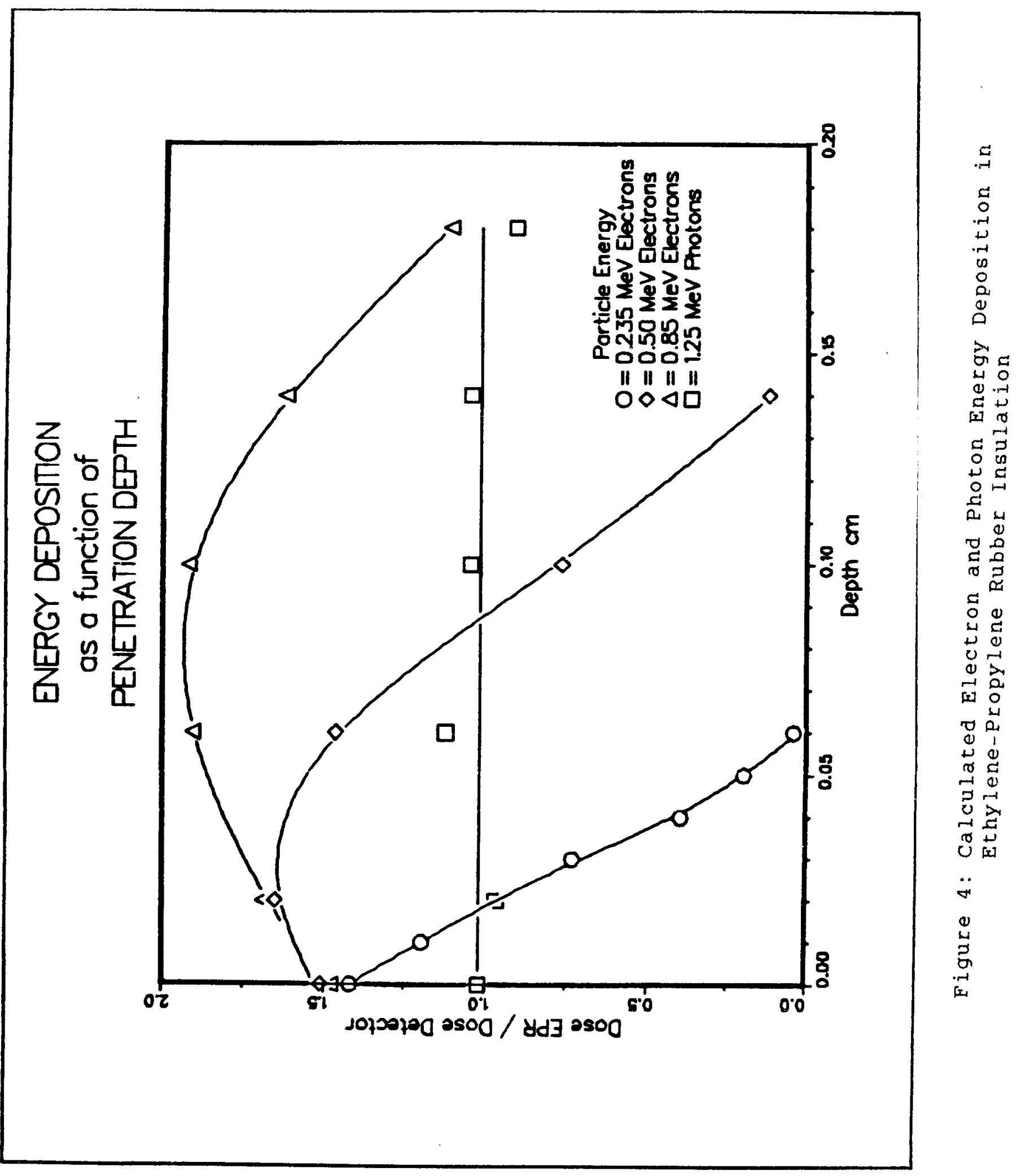


Table 1. Energy Deposition Synopsis - $0.10 \mathrm{~cm}$ EPR slab

Particle Energy Energy Hosarbed Front Surface Dose Detector Dose Energy Absorbed Front Surface Dose

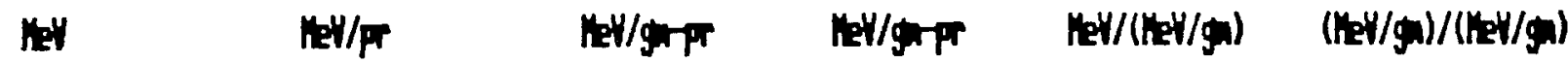

$\begin{array}{llllll}0.256 \epsilon^{-} & 0.178 & 4.89 & 3.12 & 0.022 & 1.42 \\ 0.50 \epsilon^{-} & 0.122 & 3.79 & 2.53 & 0.167 & 1.50 \\ 0.85 \epsilon^{-} & 0.388 & 2.80 & 1.88 & 0.206 & 1.49 \\ 1.26 \gamma & 0.0037 & 0.0342 & 0.055 & 0.106 & 0.974\end{array}$

Particle Energh n:"

$$
\begin{aligned}
& 0.25 \epsilon^{-} \\
& 0.50 \epsilon^{-} \\
& 0.55 \epsilon^{-} \\
& 1.5 \% \gamma
\end{aligned}
$$

Energy Atsorted / Detector Dose / o $\mathrm{HeH} /(\mathrm{HeY} / \mathrm{g}) / \mathrm{or}$

$\begin{array}{cccc} & 0.52 & 0.347 & 0.26 \\ & 1.67 & 1.27 & 0.950 \\ & 2.06 & 2.07 & 1.94 \\ & 1.06 & 1.10 & 1.19 \\ \text { Slat Thidness (a) } & 0.10 & 0.15 & 0.20\end{array}$


absorbed energy. In order to more clearly illustrate the effects of absorbed energy on material mechanical properties, all plots of material change, as a function of absorbed energy, are on the basis of absorbed energy per unit material thickness.

Extrapolated front surface dose date are listed in Table 3 . From the table it is noted that extrapolated front surface dose is not particularly sensitive to the incident electron beam energy or sample thickness. We observe, however, that the photon results are approximately fifty percent lower than the electron values. since material damage, as indicated by changes in elongation and tensile strength, may be dependent on particle energy and sample thickness and in order to demonstrate that dependence, we have tabulated front surface dose data on the basis of unit detector dose and material thickness. Plots of damage versus extrapolated front surface dose presented elsewhere, in this report, are also plotted as a function of normalized front surface dose.

For this study, a single (type) insulation material in one geometry was considered. The target material used in this study was a generic EPR rubber insulation material (\#1482) compounded from an "in-house" formulation. 2 The material was cast into a slab geometry with $15 \mathrm{~cm}$ lateral dimensions. Three sample thicknesses were used--0.1, 0.15 , and $0.20 \mathrm{~cm}$.

Full, $15 \times 15 \mathrm{~cm}$ EPR slabs were used in all radiation exposures. Integrated dose and dose-rate were fixed, for all irradiations, at 10.0 Mrad(air) and $2.0 \mathrm{Mrad}(a i r) / \mathrm{hr}$ respectively. Dose and dose-rate measurements were obtained, with calibrated thin film dosimetry, for each particle type and energy prior to any EPR exposures. Calibration of the film dosimetry was on the basis of dose to air and subsequent EPR irradiation doses were done in terms of exposure dose to air.

Radiation aging effects on bulk elastomeric materials, used in Class lE cables, are generally gauged on the basis of changes in mechanical properties of the radiation stressed material. Two frequently used indicators of radiation damage are changes in material elongation and tensile strength. In this investigation normalized elongation, e/eo, and normalized tensile strength, $\mathrm{Ts} /\left(\mathrm{Ts}_{\mathrm{O}}\right)$. were used as indicators of damage in irradiated $\mathrm{EPR}$ specimens. Irradiated samples were sectioned into test specimens 15 centimeters long by 0.625 centimeters wide. Ten specimens were taken from each sample for tensile measurements. Tensile measurements (elongation and ultimate strength) were obtained with an Instron 1000 Universal test machine using a continuous tape extensiometer graduated in 0.1 inch increments. 
Table 3. Front Surface Dose - All Slab Thicknesses

Particle Enengs

net

$0.257 \epsilon^{-}$

$0.50 \epsilon^{-}$

$0.65 \epsilon^{-}$

1. है $\gamma$
Frunt Surface bose / Betector bose / o

(lket/gn) / (net/gnl) / a

$\begin{array}{lll}14.20 & 9.46 & 7.10\end{array}$

15.00

10.00

7.50

14.90

9.93

7.45

9.74

6.19

4.87

Slat Thideress (a)

0.10

0.15

0.20 


\section{RESULTS}

\subsection{Elongation and Tensile Strength Versus Particle Energy}

Radiation exposure conditions and EPR sample data have appeared elsewhere throughout the report. For convenience, the data are sumarized as follows. All samples were exposed, in air at ambient pressure and temperature, to a fixed integrated dose and dose rate of $10 \mathrm{Mrad}$ and $2 \mathrm{Mrad} / \mathrm{hr}$ respectively. Experimental dose measurements were determined with thin film dosimetry calibrated against an air ionization chamber. Both elongation and tensile strength data were normalized on the basis of unirradiated sample results--e/eo and $\mathrm{TS}_{\mathrm{O}} / \mathrm{TS}_{\mathrm{O}}$.

Elongation results are depicted in Figure 5 . Plots $A$ and $B$. Consider Plot $A$ first. In Plot A normalized elongation data are plotted as a function of incident particle energy. Electron results appear as open circles and photon data as the open square. Each elongation value is the average elongation value for all material thicknesses irradiated at that particle energy. Error bars on the data are one standard deviation values. The solid curve drawn through the electron data is used the depict the trend of the electron data. We observe from the curve that material elongation is a slowly varying (decreasing) function of increasing electron energy. These electron data are consistant with the concept that increasing particle energy results in increasing material damage: i.e.. decreasing elongation. It may be observed that the photon data, the open square, does not track with the trend determined from the electron data.

Energy deposition in materials from photon irradiations is primarily the result of recoil electron energy loss in the irradiated material. The relationship of electron induced degradation to photon degradation data, based on the photon recoil electron energy, is given in Plot B. Figure 5. In Plot B, Figure 5 , we have again plotted the electron data as the open circles with the solid curve depicting the trend of that data. The photon recoil electron data are represented by the square symbols.

Two recoil electron energies were considered; in one case the recoil electron energy was estimated on the basis of photon absorption and total cross sections and in the other on the basis of a TIGER prediction of the recoil electron distribution within an EPR sample bombarded with $1.25 \mathrm{MeV}$ photons. The average electron energy based on photon cross section is $0.58 \mathrm{MeV}$; and when the TIGER estimate is used, the average recoil electron energy is $0.45 \mathrm{MeV}$. 


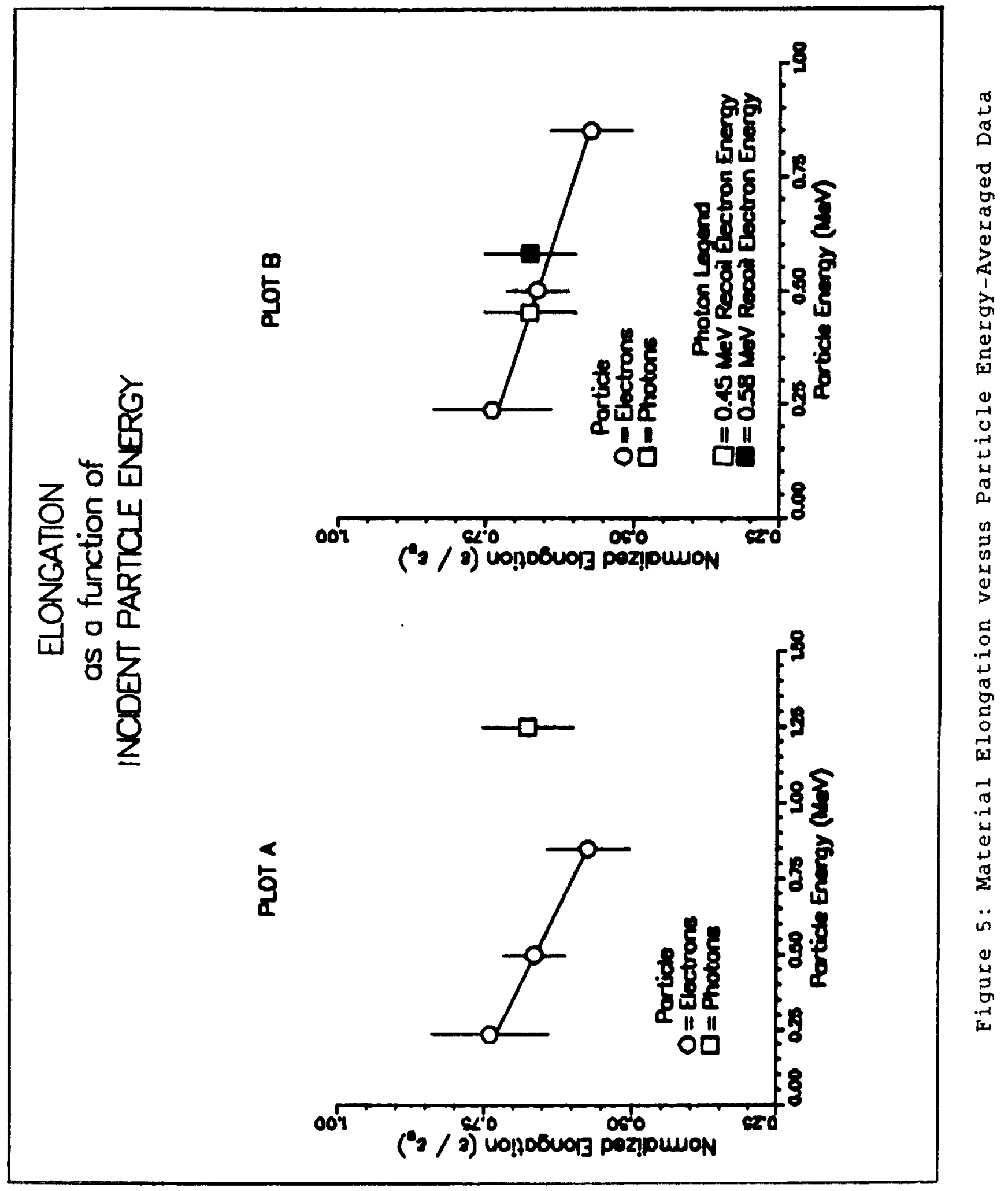


In Plot $B$, material elongation as a function of electron energy, based on the cross-section approximation, is plotted as the closed square. Data plotted on the basis of the TIGER estimate are depicted by the open square. When the photon elongation data are plotted as a function of either estimated recoil electron energy, we observe that the photon induced degradation data are in reasonable agreement with the electron degradation data. Subsequent photon degradation data are plotted as a function of the TIGER estimated recoil electron energy.

Material elongation data, depicting individual thickness data, are plotted in Figure 6 . In the figure photon elongation data have been plotted as a function of the recoil electron energy estimated on the basis of the TIGER calculation. Open, closed, and half-open symbols identify sample thickness as $0.1,0.15$, and $0.2 \mathrm{~cm}$ respectively. Error bars on individual data points are one standard deviation estimates. The solid curve is again an estimate of the degradation trend as a function of particle energy. With the exception of the data point at $0.235 \mathrm{MeV}$ and 0.93 elongation (the closed circle, sample thickness $=0.15$ ), all data were reasonably well-represented by the estimated trend. We note that the material thickness corresponding to the suspect data is bound by two sample thicknesses $(0.1$ and $0.2 \mathrm{~cm}$ ) with more consistent data points. We intend to further investigate this apparent anomolous data point in our (proposed) program designed to study the effects of lower (below $0.235 \mathrm{MeV}$ ) energy electrons.

Tensile strength data, as a function of incident particle energy, are presented in Figures 7 and 8 . The data presented in Figure 7 have been averaged over all material thicknesses for each particle energy. Electron data are depicted by the open circles, and the photon data is represented by the square symbol. Trend of the electron data is indicated by the solid curve. The photon data. square symbol, has been plotted as a function of the co60 photon recoil electron average energy, as estimated by the TIGER calculations. We note that the photon degradation data are in reasonable agreement with the electron data. The degradation trend, depicted by the solid curve, suggests that tensile strength is a slowly increasing function of incident particle energy. Tensile strength data for all particle energies and each material thickness are given in Figure 8 . Electron data are depicted by the circles, and photon data is represented by the square symbol.

\subsection{Elongation and Tensile strength versus Absorbed Energy}

In order to determine the trend of energy absorption on material degradation, elongation and tensile strength data 


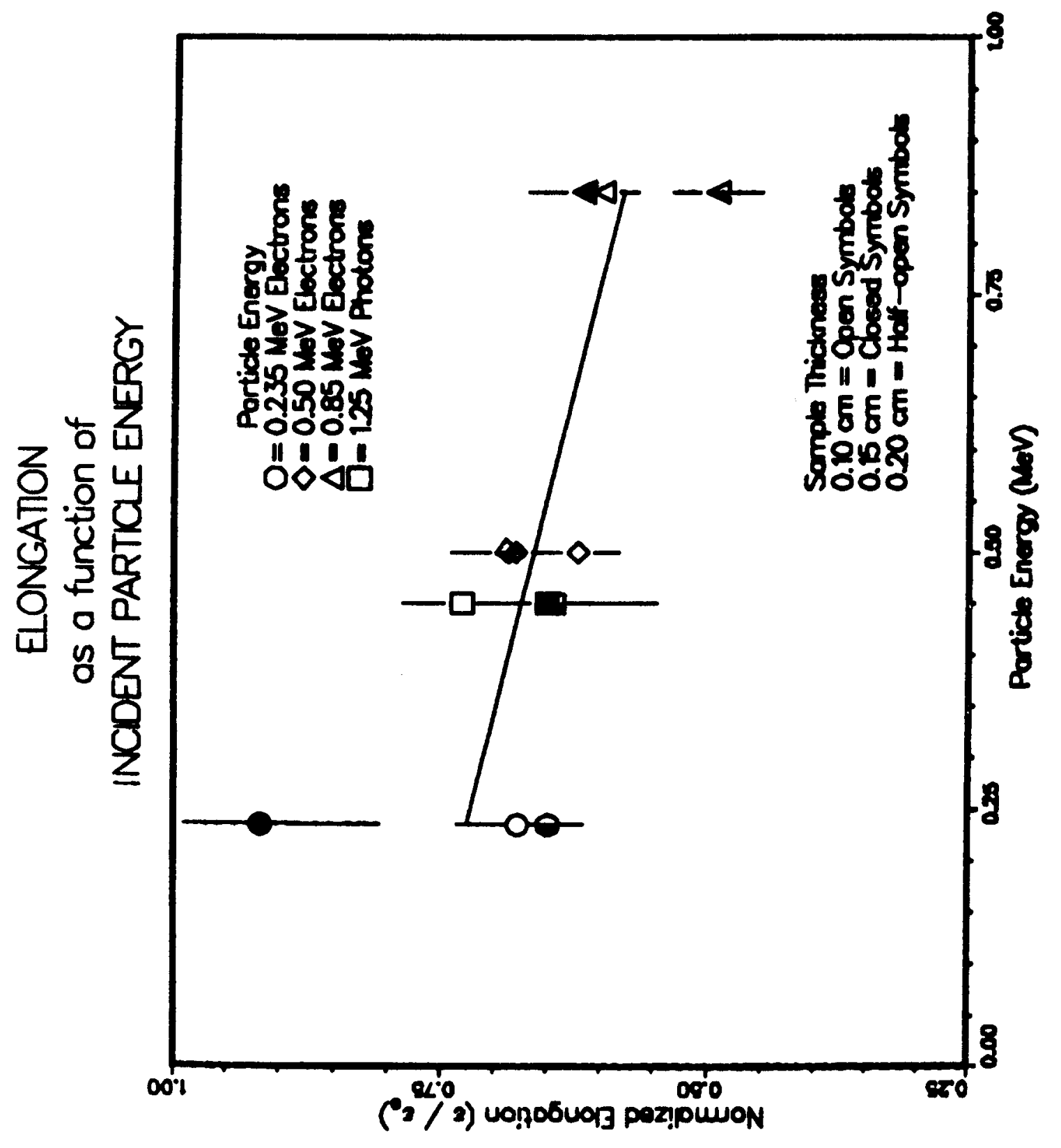




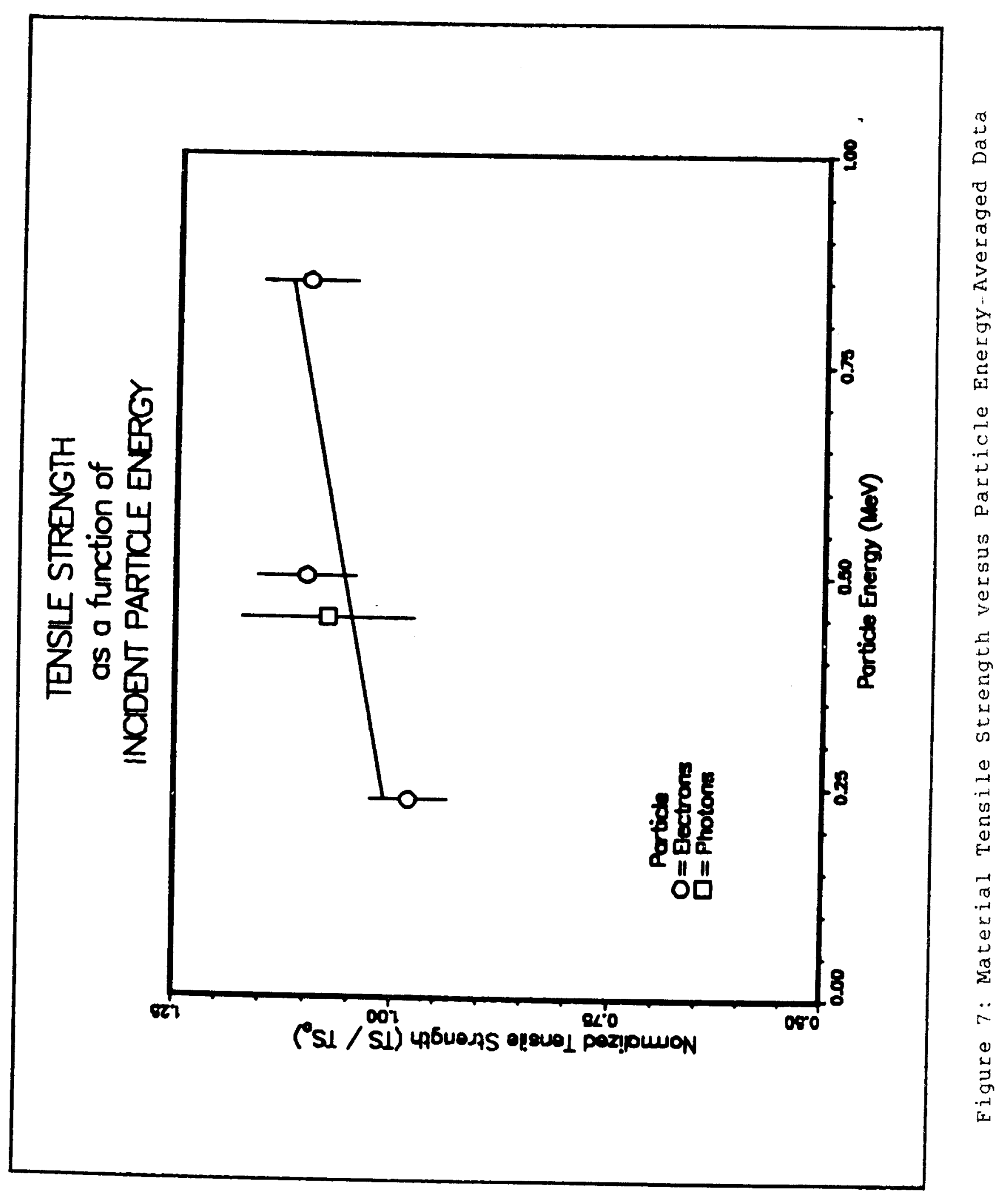




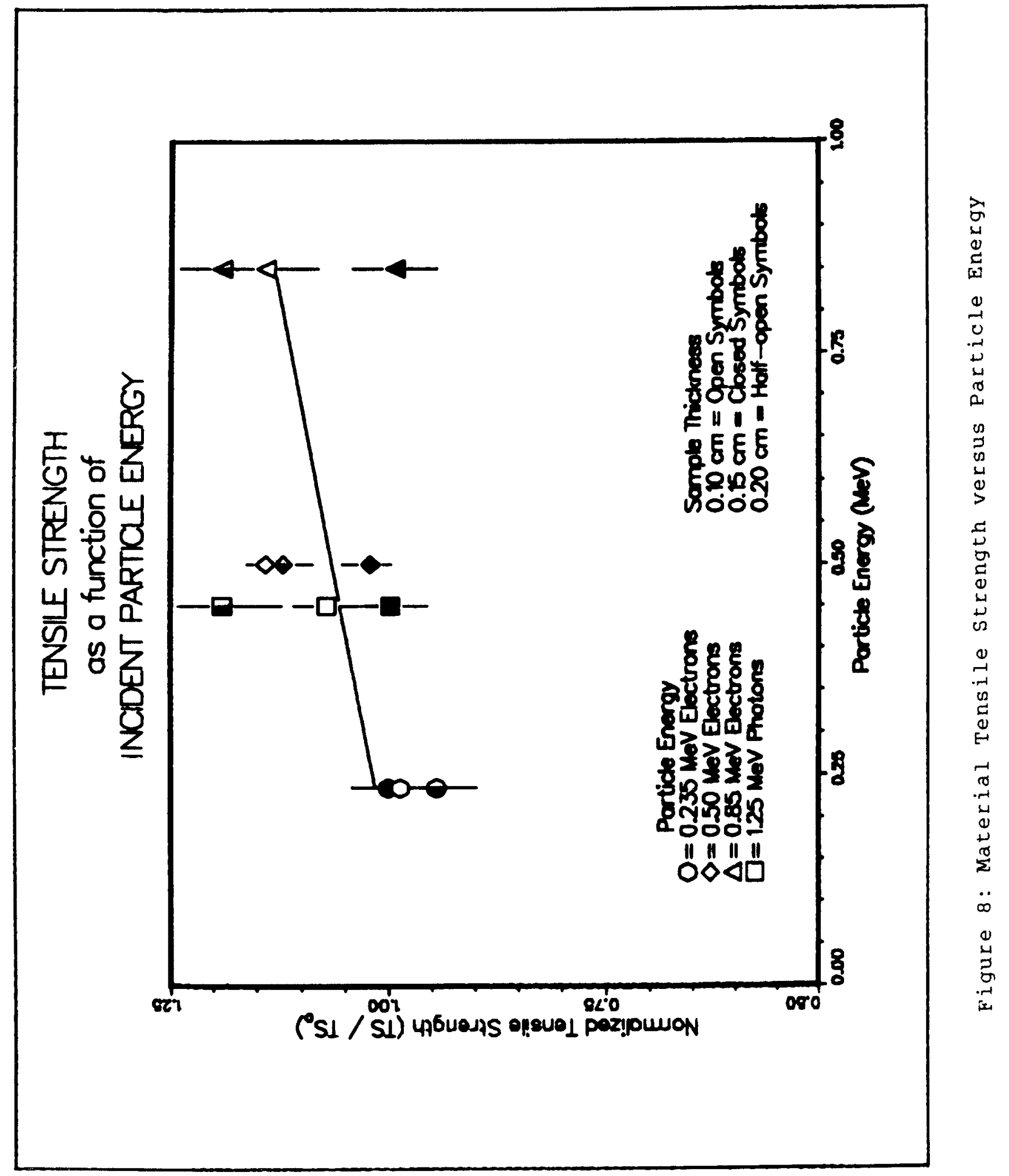


were plotted as a function of energy absorbed in the material sample. Absorbed energy estimates for the three sample thicknesses were obtained with the TIGER code and are listed in Table 2 .

Material elongation data as a function of calculated absorbed energy (Table 2) are plotted in Figure 9. Plotted are data for all particle energies and material thicknesses. Symbols are as described earlier with symbol shading being indicative of material thickness. The solid curve is an estimate of the trend in elongation as a function of absorbed energy. As may be observed in the plot elongation, degradation, is a weakly dependent function of absorbed energy per sample thickness and (largely) independent of incident particle type and deposition profile shape.

The tensile strength versus absorbed energy data are presented in Figure 10. These data are consistent with the elongation data of Figure 9 in that tensile strength is a weakly dependent function of absorbed energy and (largely) independent of both incident particle type and energy deposition profile shape.

\subsection{Elongation and Tensile Strength versus Front Surface Dose}

Elongation and tensile strength data, as a function of front surface dose, are presented in Figures 11 and 12 . Front surface dose estimates were obtained from an extrapolation of the TIGER calculations to "zero" material thickness and are compiled in Table 3 . As in the case of the absorbed energy presentations, symbol shading is indicative of material thickness and the solid curve is an estimate of data trend. From the data presented in Figure 11, we note that elongation is (weakly) dependent on the extrapolated front surface dose, decreasing with increasing front surface dose. From Figure 12 we note that the tensile strength data exhibits a similar behavior in that tensile strength is (weakly) dependent on the extrapolated front surface dose. Finally. neither plot suggests a strong dependence on particle type.

\subsection{Photon to Electron Relative Effectiveness Estimates}

The relative effectiveness of photon and electron radiation exposures to produce material degradation was estimated on the basis of the experimental elongation and tensile strength data. Effectiveness data were derived from the trend estimates of the various elongation and tensile strength data and are based on all particle energies and material thicknesses studied here. 


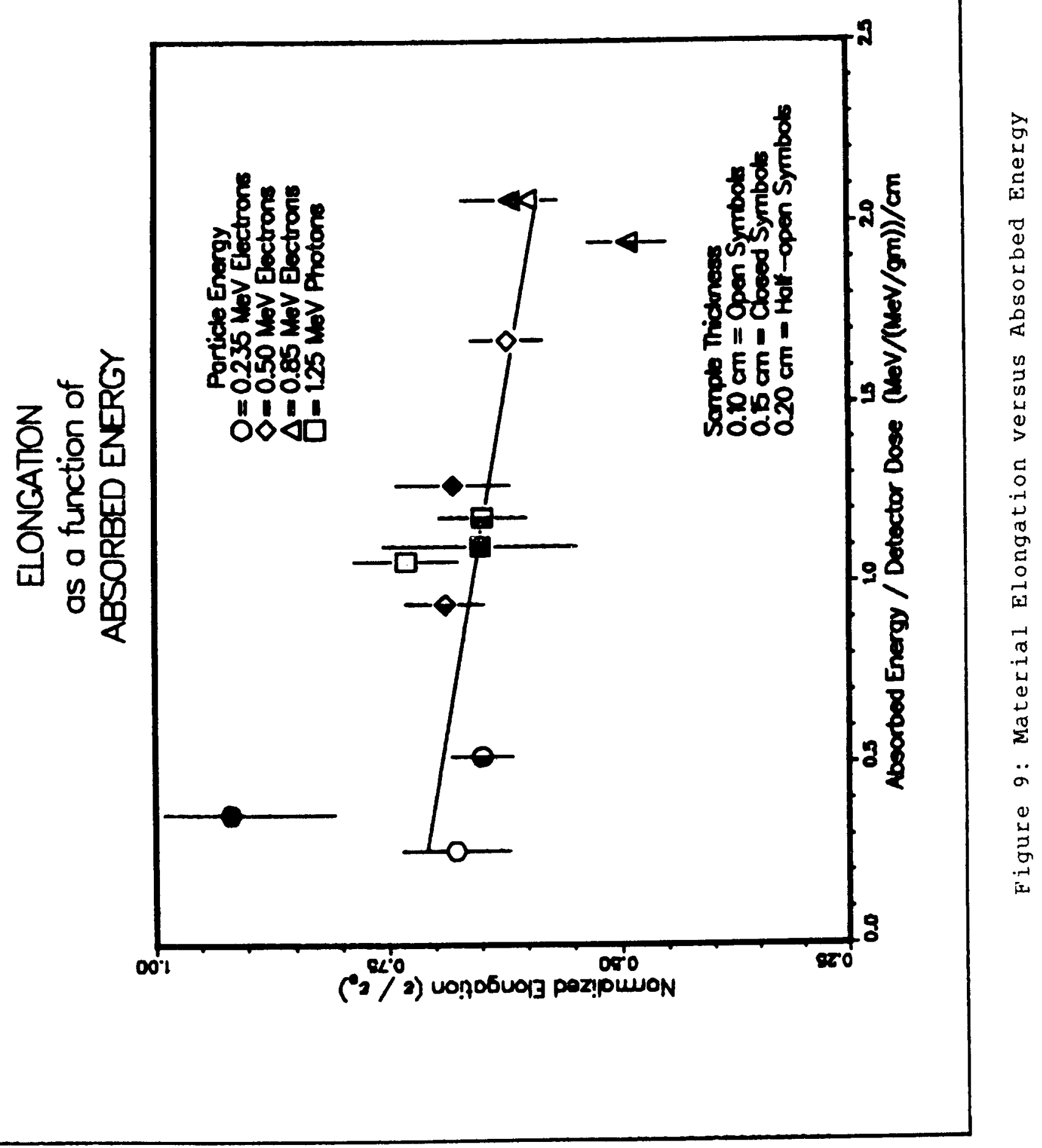




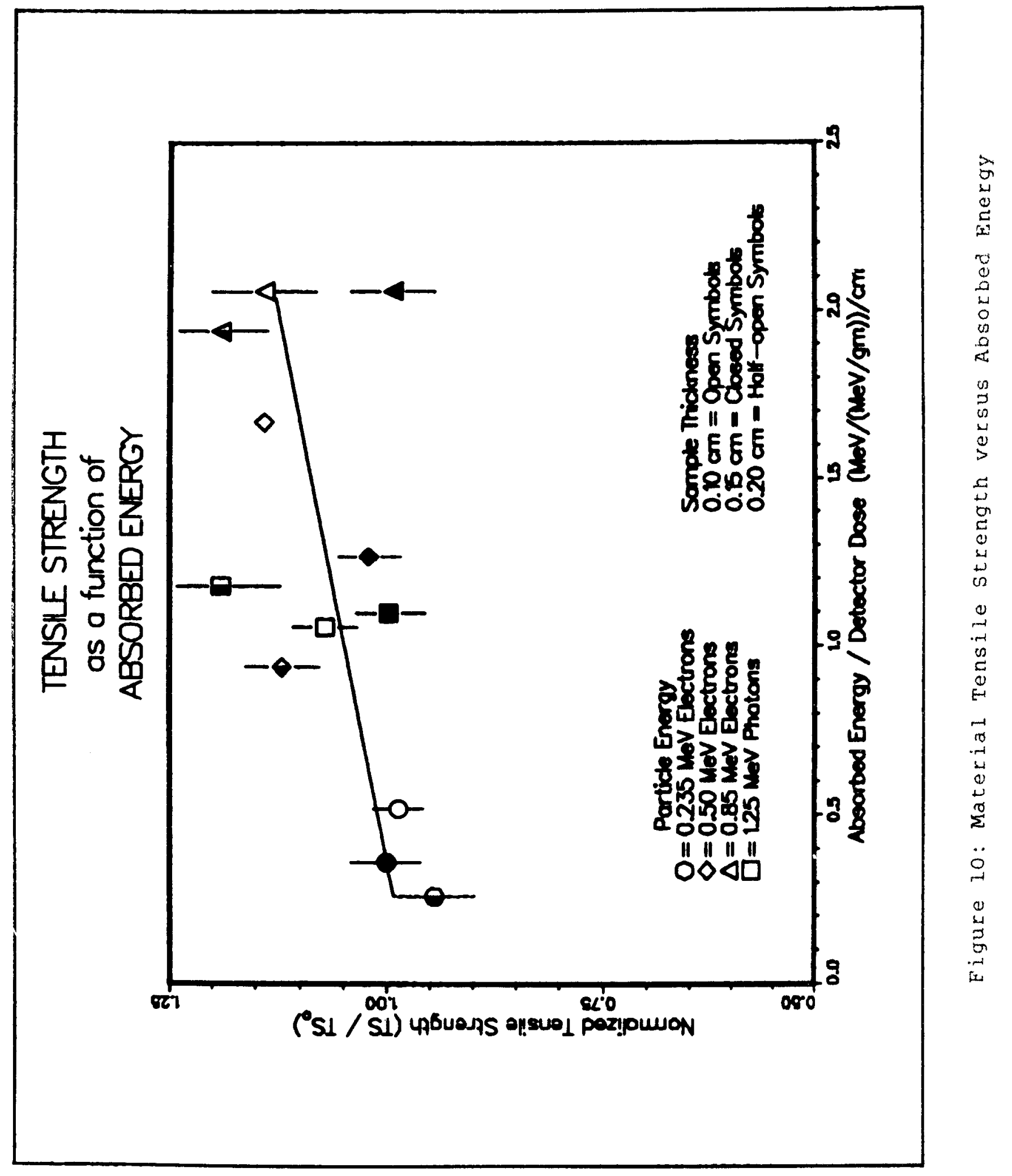




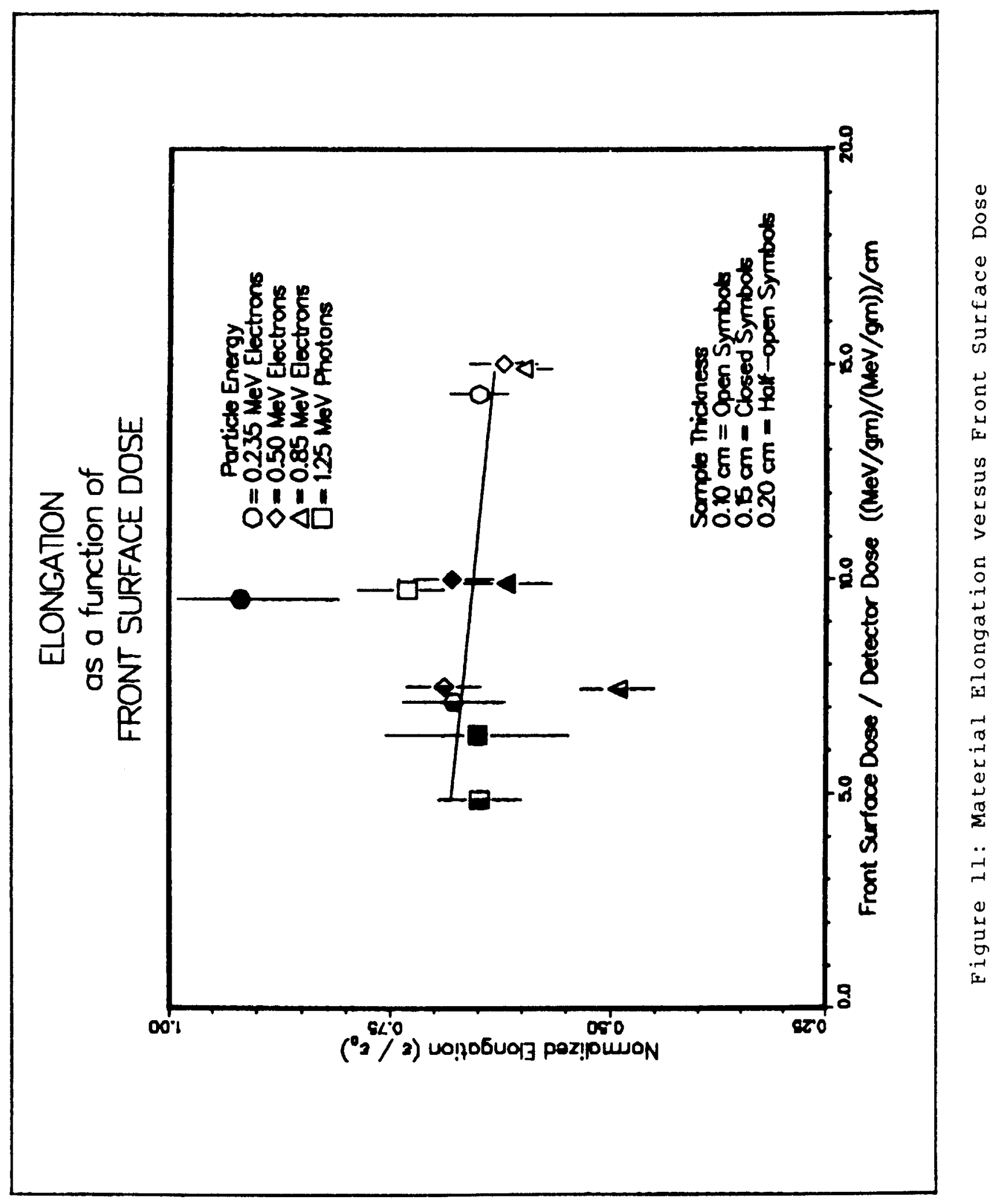




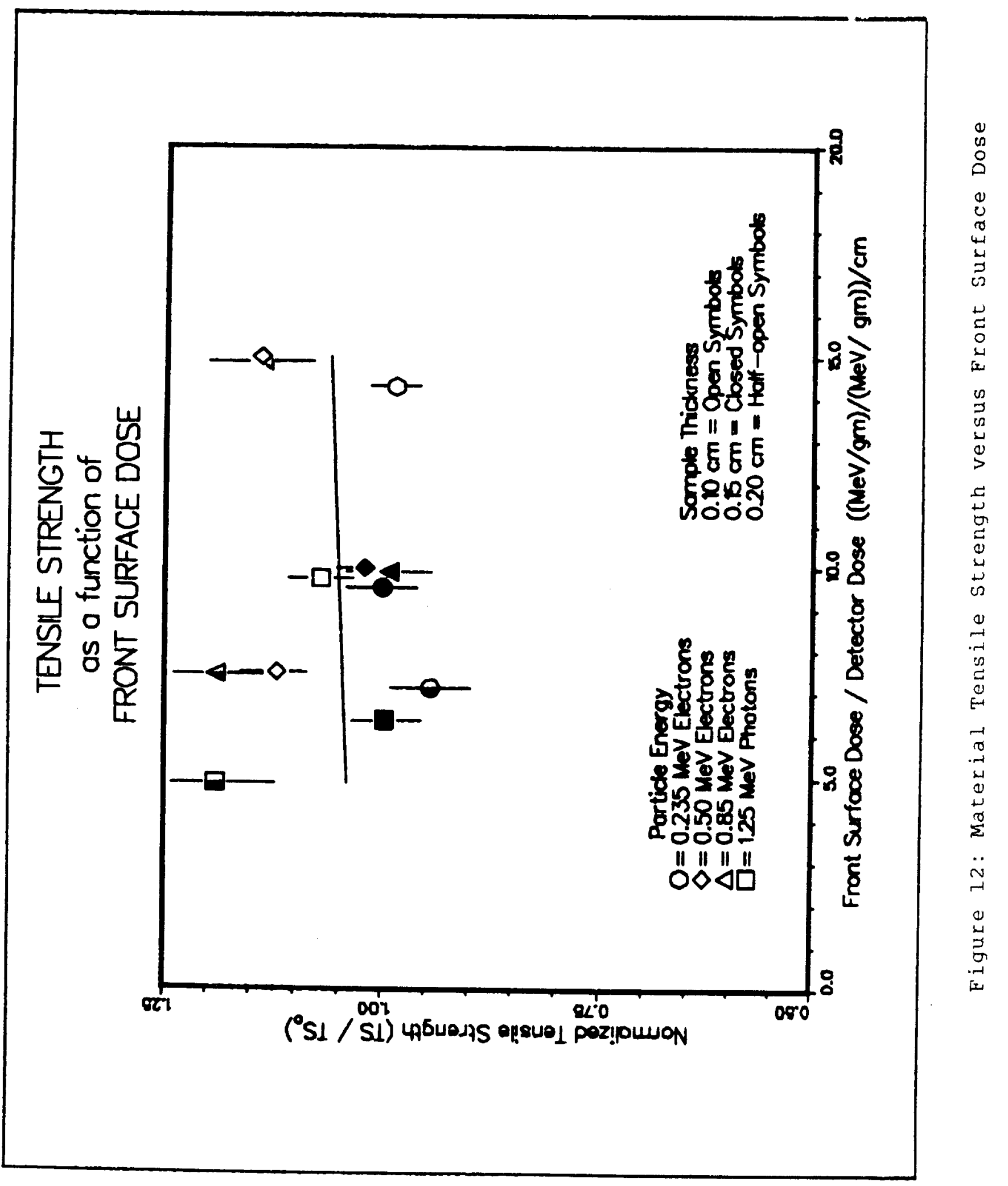


In Figure 13 the photon ( $\mathrm{Co}^{60}$ ) to electron effectiveness ratio derived on the basis of elongation data is presented. Effectiveness as a function of particle energy, absorbed energy, and front surface dose is depicted respectively by the circle, diamond, and triangle symbols. The solid curve is the simple average of the three approximations. We note that the effectiveness ratio is a slowly varying function of electron energy and lies in the range $1.0 \pm 0.07$ for all electron energies considered. Relative effectiveness values derived on the basis of tensile strength data are presented in Figure 14. These values are in good agreement with those based on the elongation data and also predict an effectiveness ratio that is weakly dependent on electron energy. The effectiveness ratio estimated on the basis of tensile strength data is also defined in the band of $1.0 \pm$ 0.07 for all electron energies.

\section{CONCLUSIONS}

As part of a simulator adequacy study, we have begun the study of the relative effectiveness of electrons and photons in producing radiation damage in a generic EPR rubber insulation material. The program was limited in extent in that a single material was used; however, three material thicknesses were selected so that a realistic range in insulation thicknesses was used in the study. The electron beam energies were selected to adequately span the LOCA estimate of average electron energies. A cobalt-60

irradiator was used to provide the photon irradiations. The study used elongation and tensile strength as indicators of radiation damage. For electron-photon equivalence purposes the damage indicators--elongation and tensile strength--were then equated to calculated values of average particle energy, material front surface dose, and absorbed energy.

Using this technique, we observed that material damage indicators were smoothly varying functions of incident electron average energy, total absorbed energy, and front surface dose. In all instances photon induced material changed tracked with the electron values--in agreement with the concept of photon-electron damage equivalence. Combined electron and photon data demonstrate that material damage, as indicated by elongation and tensile strength changes, is a slowly varying function of particle energy, absorbed energy, and front surface dose. Material thickness data indicates that, for the energies and thicknesses considered, the energy deposition distribution within the sample is not significant: rather, damage is a function only of total energy absorbed. Photon-electron relative effectiveness data, derived from the analysis of elongation and tensile strength information, predicts that photon to electron equivalence is a 


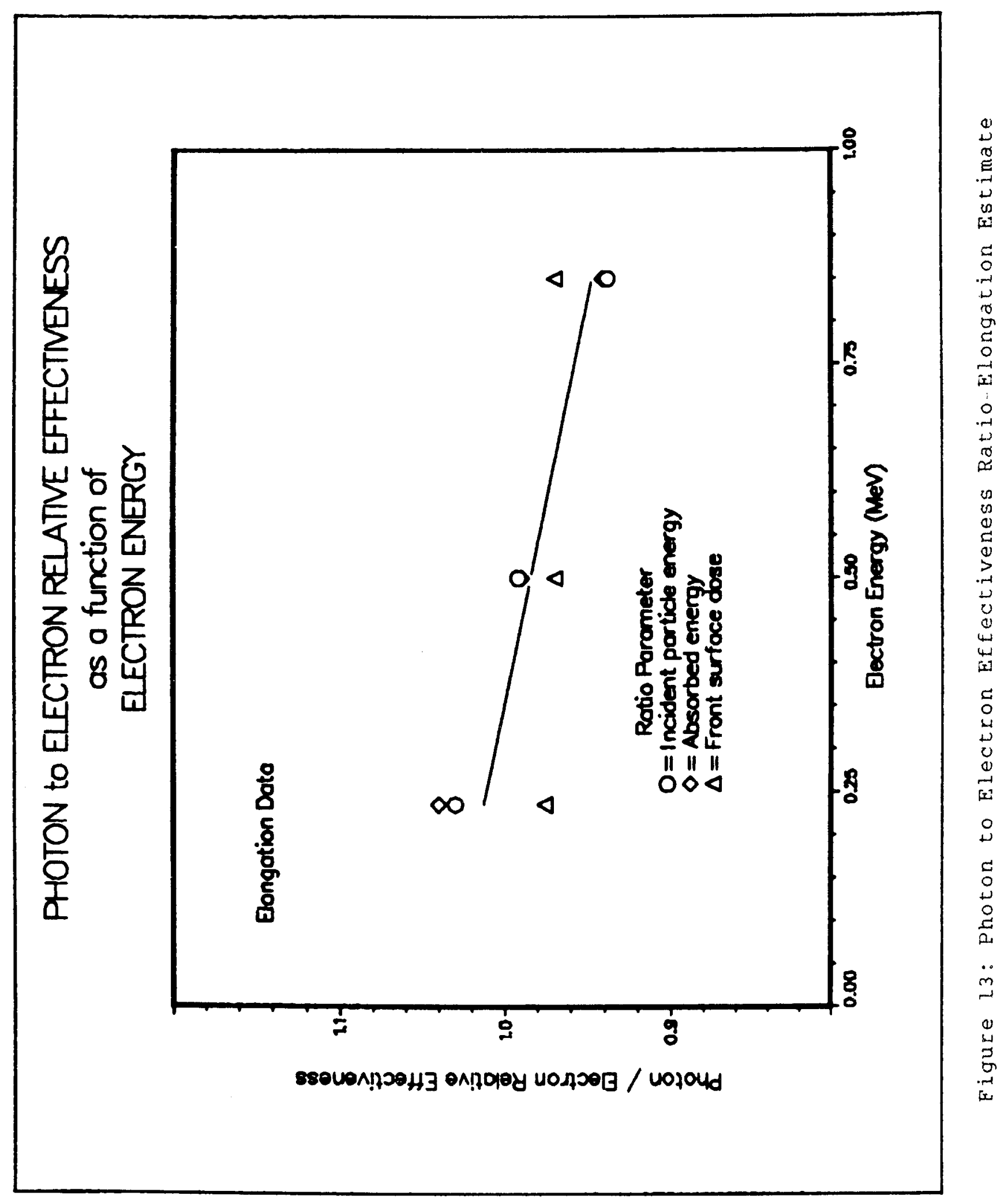




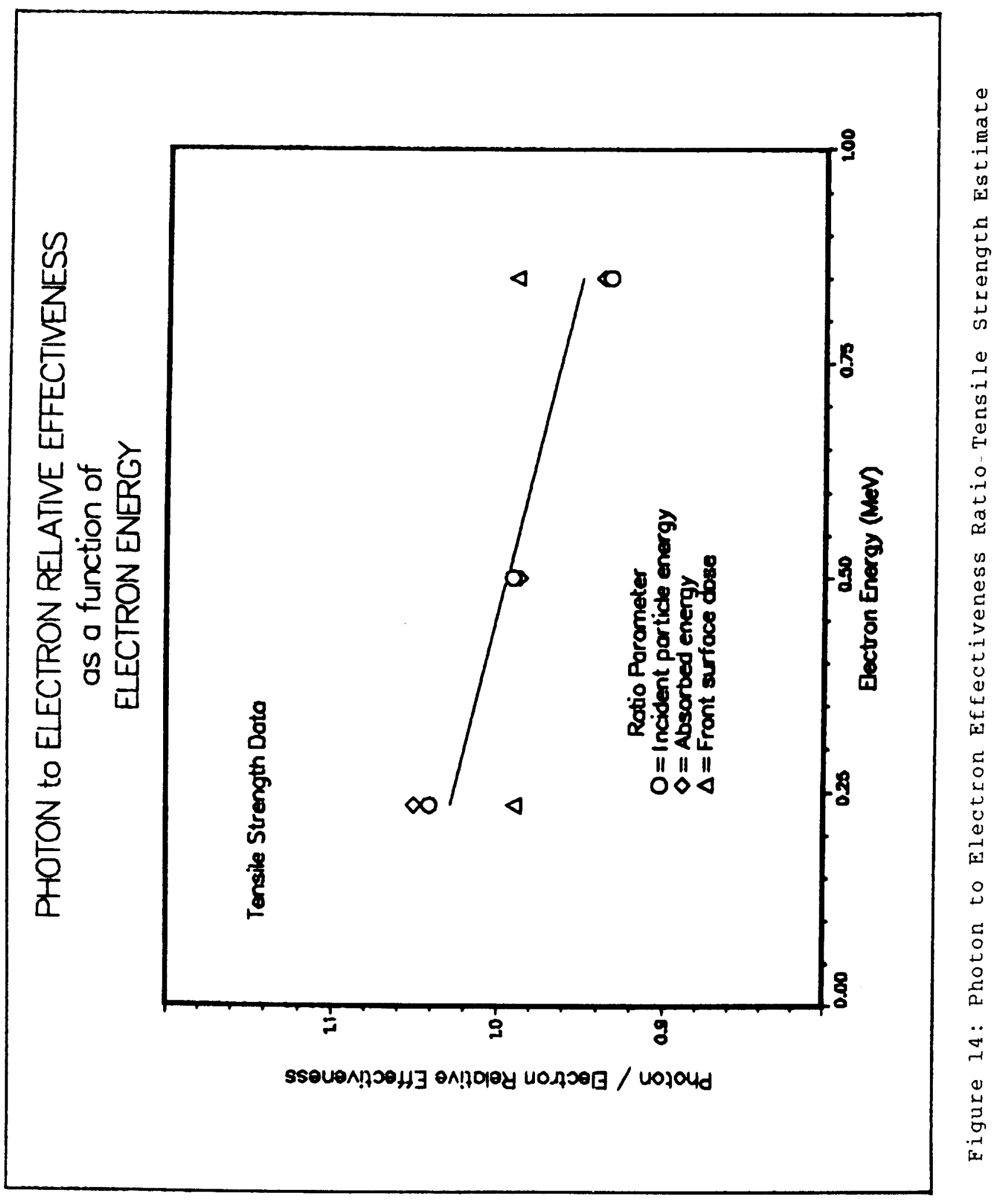


linear function of incident electron energy and that incident particle energy, absorbed energy, and front surface dose are equally dependable estimations of photon and electron equivalence. From a practical point of view, front surface dose measurements may provide the most straightforward method of comparing electron and photon effects experiments.

Although the equivalence between photon and electron irradiations has been demonstrated on the basis of these experiments, it is believed additional studies are warranted. In addition to considering another, higher integrated dose, we believe the program should be extended to include at least one other material formulation as a test to the uniqueness of these results. Further, lower energy electron beam irradiations should be considered so that the effects, if any, of energy deposition profile could be examined further. This effort might establish a lower, practical limit on the LOCA electron spectrum. Finally, we are aware that dose-rate effects are influencing the results

presented in this report. It may be observed from Figures 4 and 9 (or 10) that, for a constant detector dose, as electron energy is increased dose per unit (material) thickness, integrated dose, and dose rate in the material interior will also increase. From data not tabulated here, we noted that material response is a sensitive function of dose-rate, as determined with the detector for dose-rates below 2 to $3 \mathrm{Mrad} / \mathrm{hr}$. It is suggested that this doserate dependence results in a decrease in the effectiveness of higher energy electrons thus flattening the response (as a function of energy) curves. Although the dose rate used in this study is representative of LOCA dose rates, further work at other dose rates necessary to more adequately investigate the dose-rate effects on the effectiveness of higher energy electrons may be warranted. 


\section{REFERENCES}

1. L. L. Bonzon and W. H. Buckalew, Evaluation of Simulator Adequacy for the Radiation Qualification of Safety Related Equipment, SAND79-1787, NUREG/CR-1184, Sandia National Laboratories, January 1980.

2. E. A. Salazar, D. A. Bouchard, and D. T. Furgal, Aging with Respect to Flammability and other Properties in Fire-Retarded Ethylene Propylene Rubber and Chlorosulfonated Polyethelyne. SAND81-1906, NUREG/CR-2314, Sandia National Laboratories. March 1982 .

3. L. L. Bonzon, N. A. Lurie, D. H. Houston, and J. A. Nuber, Definition of Loss of Coolant Accident Radiation Source: Summary and Conclusions. SAND78-0091. Sandia National Laboratories. May 1976.

4. L. L. Bonzon, Radiation Signature Following the Hypothesized LOCA, SAND76-0740, NUREG76-6521, Sandia National Laboratories, Rev. October 1977.

5. G. H. Miller and G. J. Lockwood, IEEE Trans. Nucl. Sci.. NS-22, 1072 (1975).

6. W. H. Buckalew, G. J. Lockwood, S. M. Luker, L. E. Ruggles, F. J. Wyant, Capabilities and Diagnostics of the Sandia Pelletron-Raster System, SAND84-0912, NUREG/CR-3777, Sandia National Laboratories. July. 1984.

7. J. A. Halbleib, Sr., and W. H. Vandevender, Nucl. Sci. Eng.. 57. 94 (1975). 


\section{DISTRIBUTION :}

U.S. Government Printing office Receiving Branch (Attn: URC stock) 8610 Cherry Lane

Laure 1, MD 20707

375 copies for RV

Ansaldo Impianti

Centro Sperimentale del Boschetto

Corso F.M. Perrone, 118

16161 Genova

ITALY

Attn: C. Bozzolo

Ansaldo Impianti

Via Gabriele D'Annunzio, 113

16121 Genova

ITALY

Attn: S. Grifoni

ASEA-ATOM

Department KRD

Box 53

S-721 04

Vasteras

SWEDEN

Attn:

A. Kjellberg

ASEA-ATOM

Department TQD

Box 53

S-721 04

Vasteras

SWEDEN

Attn: T. Granberg

ASEA KABEL AB

P.O. BOX 42108

S-126 12

Stockholm

SWEDEN

Attn: B. Dellby

Atomic Energy of Canada, Ltd. Chalk River Nuclear Laboratories Chalk River, Ontario KOJ 1JO CANADA

Attn: G. F. Lynch
Atomic Energy of Canada, Ltd. 1600 Dorchester Boulevard West Montreal, Quebec H3H 1P9 CANADA

Attn: S. Wish

Atomic Energy Research Establishment Building 47, Division K.D.D.

Harwell, oxfordshire

OXI1 ORA,

ENGLAND

Attn: S. G. Burnay

Bhabha Atomic Research Centre

Health Physics Division

BARC

Bombay-85

INDIA

Attn: S. K. Mehta

British Nuclear Fuels Ltd.

Springfields Works

Salwick, Preston

Lancs

ENGLAND

Attn: W. G. Cunliff, Bldg 334

Brown Boveri Reaktor GMBH

Postfach 5143

D-6800 Mannheim 1

WEST GERMANY

Attn: R. Schemmel

Bundesanstalt fur Materialprufung Unter den Eichen 87

D-1000 Berlin 45

WEST GERMANY

Attn: K. Wundrich

CEA/CEN-EAR

Departement de surete Nucleaire Service d'Analyse Fonctionnelle B.P. 6

92260 Fontenay-aux-Roses FRANCE

Attn: M. Le Meur

$J$. Kenry 
CERW

Laboratorie 1

CH-1211 Geneve 23

SWITZERLAND

Attn: H. Schonbacher

Canada Wire and Cable Limited

Power \& Control Products Division

22 Commercial Road

Toronto, Ontario

CANADA M4G 124

Attn: $Z$, S. Panici

Centro Elettrotecnico Sperimentale Italiano

Research and Development

Via Rubattino 54

20134 Milan,

ITALY

Attn: Carlo Hasetti

Commissariat a $1^{\prime}$ Energie Atomique ORIS/LABRA

$B P N^{\circ} 21$

91190 Gif-Sur-Yvette

ERANCE

Attn:

G. Gaussens

$\mathrm{J}$. Chenion

E. Carlin

Commissariat a $1^{\prime}$ Energie Atomique CEN Cadarche DRE/STRE

BP $\mathbf{N}^{\circ} \mathbf{1}$

13115 Saint Paul Lez Durance

FRANCE

Attn: J . Campan

Conductores Monterrey, S. A.

P.O. Box 2039

Monterrey, $\boldsymbol{N}$. L.

MEXICO

Attn: P. G. Murga

Electricite de France

(S.E.P.T.E.N.)

12, 14 Ave. Dubrieroz

69628 Villeurbarnie

Paris, FRANCE

Attn: H. Herouard

M. Hermant
Electricite de Erance

Direction des Etudes et Recherches

1, Avenue du General de Gaulle

92141 CLAMART CEDEX

ERANCE

Attn: J. Roubault

L. Deschamps

Electricite de Erance

Direction des Etudes et Recherches

Les Renardieres

Boite Postale $n^{\circ} 1$

77250 MORET SUR LORING

ERANCE

Attn: Ph. Roussarie

V. Deglon

J. Ribot

Energia Nucleare e delle

Energie Alternative

CKE Casaccia

1-0060 Rome

ITALY

Attn: A. Cabrini

EURATOM

Commission of European Communities

C.E.C. J.R.C.

21020 Ispra (Varese)

ITALY

Attn: $G$. Mancini

ERAMATOME

Tour Fiat - Cedex 16

92084 Paris La Defense

ERANCE

Attn: G. Chauvin

E. Raimondo

Eurukawa Electric Co., Ltd.

Hiratsuka Wire Works

1-9 Higashi Yawata - 5 Chome

Hiratsuka, Kanagawa Pref

JAPAN 254

Attn: E. Oda

Gesellschaft fur Reaktorsicherheit (GRS) $\mathrm{mbH}$ Glockengasse 2

D-5000 Koln 1

WEST GERMANY

Attn: Library 
Health \& Safety Executive

Thames House North

Milbank

London SWIP 4QJ

ENGLAND

Attn: W. W. Ascroft-Hutton

ITT Cannon Electric Canada

Eour Cannon Court

Whitby, Ontario LId 5 V8

CANADA

Attn: B. D. Vallillee

Imatran Voima oy

Electrotechn. Department

P.O. Box 138

SF-00101 Helsinki 10

EIMLAND

Attn: B. Regnell

K. Koskinen

Institute of Radiation Protection Department of Reactor Safety

P.O. Box 268

00101 Helsinki 10

EIULAND

Attn: L. Reiman

Instituto de Desarcollo y Diseno

Ingar - Santa Fe

Avellaneda 3657

C.C. $34 \mathrm{~B}$

3000 Santa Fe

REPUBLICA ARGENTINA

Attn: $\mathbf{N}$. Labath

ISMES S.P.A.

Viale G. Cesare, 29

24100 BERGAMO, Italy

Attn: A. Castoldi

M. Salvetti

Japan Atomic Energy Research Institute

Takasaki Radiation Chemistry

Research Establishment

Watanuki-machi

Takasaki, Gunma-ken

JAPAN

Attn: N. Tamura

K. Yoshida

T. Seguchi
Japan Atomic Energy Research Institute Tokai-kura

vaka-Gun

Ibaraki-Ken

319-11, JAPAN

Attn: $Y$. Koizumi

Japan Atomic Energy Research Institute Osaka Laboratory for Radiation Chemistry 25-1 Mii-Minami machi,

Neyagawa-shi

Osaka 572

JAPAN

Attn: $Y$. Nakase

Kalle Niederlassung der Hoechst AG Postfach 3540

6200 Wiesbaden 1 ,

WEST GERMANY

Biebrich

Attn: Dr. H. Wilski

Kraftwerk Union AG

Department R361

Hammerbacherstrasse $12+14$

D-8524 Erlangen

WEST GERMANY

Attn: I. Terry

Kraftwerk Union AG

Section R541

Postfach: 1240

D-8757 Karlstein

WEST GERMANY

Attn: W. Siegler

Kraftwerk Union AG

Hammerbacherstrasse $12+14$

Postfach: 3220

D-8520 Erlangen

WEST GERMANY

Attn: W. Morell

Motor Columbus

Parkstrasse 27

CH-5401

Baden

SWITZERLAND

Attn: H. Fuchs 
National Nuclear Corporation

Cambridge Road, Whetstone

Leicester LE8 3LH

ENGLAND

Attn: A. D. Hayward

J. V. Tindale

wOK AG Baden

Beznau Wuclear Power Plant

CH-5312 Doettingen

SWITZERLAND

Attn: 0 . Tatti

Morsk Kabelfabrik

3000 Drammen

NORWAY

Attn: C. T. Jacobsen

Nuclear Power Engineering Test Center 6-2, Toranomon, 3-Chome

Minato-ku, \#2 Akiyana Bldg.

Tokyo 105

JAPAN

Attn:

K. Takumi

Ontario Hydro

700 University Avenue

Toronto, Ontario M5G $1 \times 6$

CANADA

Attn: $R$. Wong

B. Kukreti

Oy Stromberg $A b$

Helsinki Works

Box 118

FI-00101 Helsinki 10

EIQLAND

Attn: P. Paloniemi

Radiation Center of Osaka Prefecture

Radiation ApplicationPhysics Division

Shinke-Cho, Sakai

Osaka, 593, JAPAN

Attn: S. Okamoto

Rappinl

ENEA-PEC

Via Arcoveggio 56/23

Bologna

ITALY

Attn: Ing. Ruggero
Rheinisch-Westfallscher

Technischer Uberwachunge-Vereln e.v.

Postfach 103261

D-4300 Essen 1

WEST GERMANY

Attn: B. Sartori

Sydkraft

Southern Sweden Power Supply

21701 Malmo

SWEDEW

Attn: 0 . Grondalen

Technical University Munich

Institut for Radiochemie

D-8046 Garching

WEST GERMANY

Attn: Dr. H. Heusinger

UKAEA

Materials Development Division

Building 47

AERE Harwell

OXON OXI1 ORA

ENGLAND

Attn: D. C. Phillips

United Kingdom Atomic Energy Authority

Safety \& Reliability Directorate

Wigshaw Lane

Culcheth

Warrington WA3 4NE

ENGLAND

Attn: M. A. H. G. Alderson

Waseda University

Department of Electrical Engineering

3-4-1 Ohkubo, Shinjuku-ku

Tokyo 160

JAPAN

Attn: Y. Ohki 


$\begin{array}{ll}1200 & \text { J. P. Vandevender } \\ 1231 & \text { J. A. Halbleib } \\ 1234 & \text { G. J. Lockwood } \\ 1800 & \text { R. L. Schwoebel } \\ 1810 & \text { R. G. Kepler } \\ 1811 & \text { R. L. Clough } \\ 1812 & \text { J. M. Zeigler } \\ 1812 & \text { K. T. Gillen } \\ 1813 & \text { J. G. Curro } \\ 2126 & \text { J. E. Gover } \\ 2126 & \text { O. M. Stuetzer } \\ 6200 & \text { V. L. Dugan } \\ 6300 & \text { R. W. Lynch } \\ 6400 & \text { A. W. Snyder } \\ 6410 & \text { J. W. Hickman } \\ 6417 & \text { D. D. Carlson } \\ 6420 & \text { J. V. Walker } \\ 6433 & \text { F. V. Thome } \\ 6440 & \text { D. A. Dahlgren } \\ 6442 & \text { W. A. Von Riesemann } \\ 6444 & \text { L. D. Buxton } \\ 6446 & \text { L. L. Bonzon (10) } \\ 6446 & \text { W. H. Buckalew (5) } \\ 6446 & \text { L. D. Bustard } \\ 6446 & \text { J. W. Grossman } \\ 6446 & \text { M. J. Jacobus } \\ 6446 & \text { J. D. Keck } \\ 6446 & \text { F. J. Wyant } \\ 6447 & \text { D. L. Berry } \\ 6449 & \text { K. D. Bergeron } \\ 6450 & \text { J. A. Reuscher } \\ 8024 & \text { P. W. Dean } \\ 3141 & \text { S. A. Landenberger (5) } \\ 3151 & \text { W. L. Garner } \\ & \end{array}$





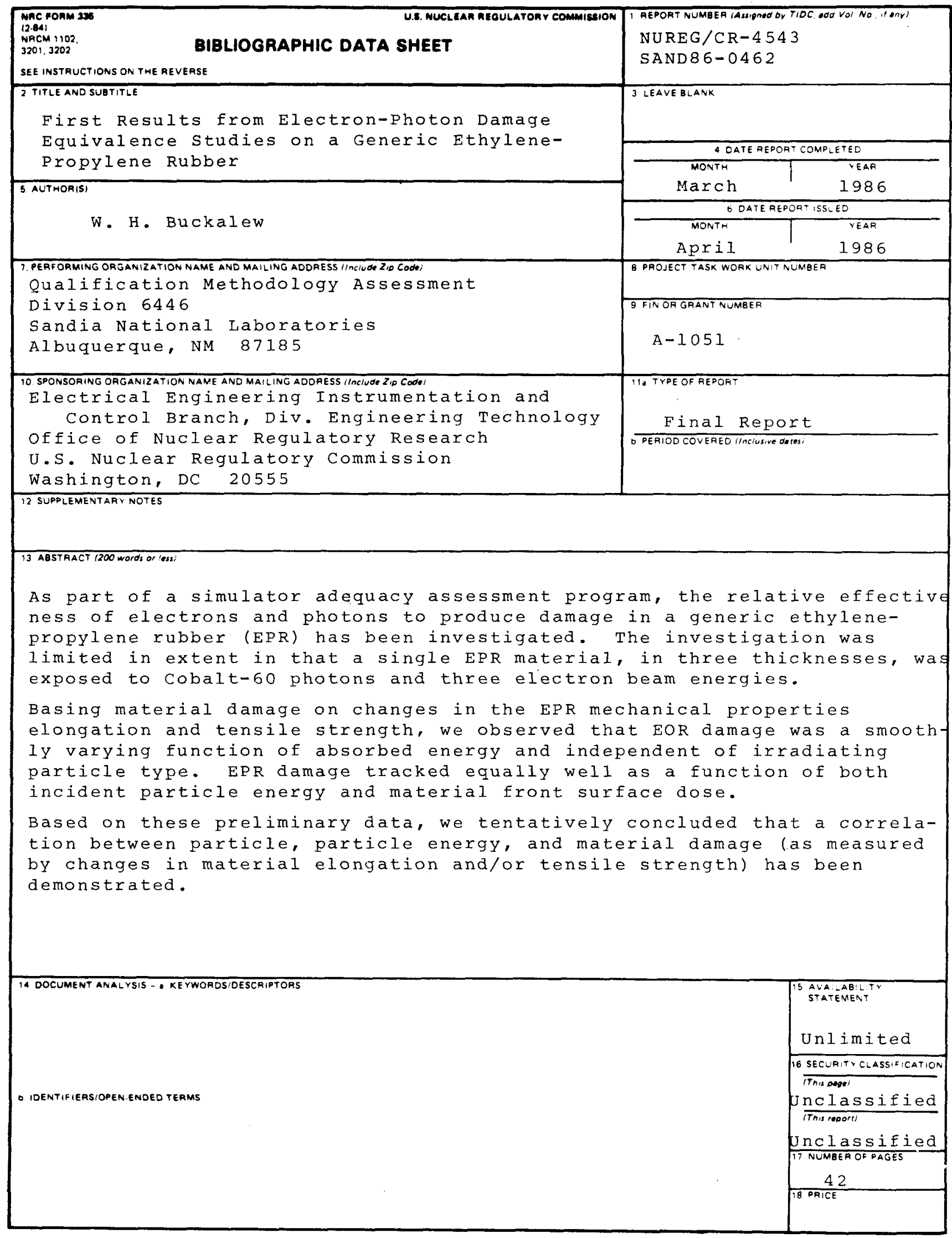

